\title{
ORGANIZATIONAL CREATIVITY \\ AND TASK ENVIRONMENT: AN INTERACTIONIST PERSPECTIVE
}

The main objective of this article is to connect the interactionist view to organizational creativity and task environment research to implications for firm performance. The framework represents an attempt to examine relationships between organizational creativity and task environment in a systematic and nuanced manner, with the objective of understanding why these interactions may advance firm performance. The article presents the development of the typology of five types of organizational creativity - task environment interactions producing different organizational effects. Collectively, the authors' arguments expand, and in some respects, challenge the theory of organizational creativity, and open new windows into the study of its relationship with firm performance.

Keywords: organizational creativity, task environment, firm performance, interactionist perspective

DOI: $10.15611 /$ aoe.2018.1.13

\section{INTRODUCTION}

It is well-documented that firms respond and try to influence their environments ${ }^{1}$. The purpose of this paper is to contribute to the author's understanding of organizational creativity by further unpicking what is organizational creativity and what environmental conditions may support or hinder firm performance, especially in relation to organizational creativity task environment interactions. Whereas the author's review of creativity literature reveals that little research has been done to explore the environmental conditions under which organizational creativity is more and less likely to fuel firm performance. Researchers have found evidence that the predictive validity of organizational creativity is altered when

\footnotetext{
* Department of Entrepreneurship and Management Innovation, University of Economics in Katowice.

${ }^{1}$ This is the modified version of the paper presented at International Academic Conference on Management, Economics, Business and Marketing, Vienna 2016. The author would like to thank discussants for the insightful comments. All remaining errors are, of course, my own. The author appreciates the financial support from the National Scientific Centre (grant no 2015/17/B/HS4/00935).
} 
considering environmental differences (e.g. Sarooghi, Libaers, Burkemper, 2014).

The author's aim is to take stock of research in line with Zhou and Hoever's (2014) interactionist account of creativity in organizations. Using this typology yields various interesting insights into the complex interplay of the (a) stable or transient characteristics of an organizational creativity and (b) contextual, task environment factors. The author used contextualizing (representational model) to improve the fit between concepts in the interactionist model and the specific phenomena in the real managerial practice (Harris, Johnson, Souder, 2013). The author's theoretical study enables increased precision in researching organizational creativity: reassessing the contributions of existing salient research and extending previous literature, and explaining the implications of this stream of research.

The theoretical arguments demonstrate that creative firms choose to respond in different task environments. Of particular interest is finding that interactions between organizational creativity and task environment influence firm performance, that is, firms perform highly or not in such interactions' context. Therefore, in addition to furthering our understanding of how organizational creativity is shaped by environment, the author documents a novel way in which the interaction of positive and negative organizational creativity characteristics with supportive and inhibiting task environment, shape firms' performance actions as they compete for favourable strategic position.

The paper is organized in three main sections. The author reviews the extant literature on creativity and environment to unveil some conceptualizations, and explores the organizational creativity further in the second section by presenting the theoretical findings from the review, having first outlined the methodological approach. These findings provide new insights into organizational creativity by exposing five types of interactions between organizational creativity and task environment which are expected to influence firm performance. The author promotes the view of organizational creativity as a process that acknowledges interactions with the environment as a key aspect of the creative effects on firm performance. The paper concludes by outlining the main implications for future research in organizational creativity, distilling key considerations for advancing studies in relation to creativity issues that can have a positive impact on management practice. 


\section{ORGANIZATIONAL CREATIVITY AND TASK ENVIRONMENT. DEFINING THE CONSTRUCT AND THEIR DIMENSIONS}

It is generally believed that creativity enhances firm's performance, driving business competitiveness and prosperity (Porter, Rivkin, 2012). Creativity in an organization is usually defined as an outcome - i.e. products, services, business models, work methods, or management processes that are novel and useful (Zhou, Hoever, 2014). In the field studies, creativity is usually measured by scales that assess both novelty and usefulness (Amabile, Pillemer, 2012). Drawing on the past research on creativity in organizations and dynamic capabilities, the author suggests the following definition: organizational creativity is the firm's ability to generate new and useful ideas to address rapidly changing opportunities and threats by making timely and market-oriented decisions, and to frame breaking changes in its resource base (Bratnicka, 2012). Hence, the author considers novelty and usefulness as two distinct dimensions of organizational creativity. Thus, some may see tensions between creative novelty and creative usefulness, in fact the two are natural bedfellows. To sum up, if an organization lacks the resources to implement the idea, its performance would be unaffected by novelty. In a somewhat different tone, an organization may be highly skilled at implementing novel ideas, but if it has nothing to implement, its performance would be unaffected.

Most attempts to conceptualize and measure the characteristics of what the author labels organization creativity, describing two main characteristics or dimensions - novelty and usefulness. The author conceptualized organizational creativity as type IV second-order hierarchical latent variable model (Becker, Klein, Wetzels, 2012). Organizational creativity is a multidimensional concept which consists of two dimensions (creative novelty and creative usefulness) and exists in six sub dimensional domains originality, compatibility, malleability, competitive advantage, appropriability, and internal fit (Bratnicka, 2014).

Flipo (2014) considers idea selection as a critical mechanism, which significantly impacts team creativity. Others underline the key role of the creative ideas selection (Li, Maggitti, Smith, Tesluk, Katila, 2013). Naturally, creative usefulness is important for value creation and appropriation. More specifically, the evaluation and selection process of corporate ventures is driven by novelty and strategic alignment in the initial phase of venture development (Masucci, Brusoni, Hayton, 2014). Following these ideas, the author poses that six sub-dimensions of organizational 
creativity are key selection criteria. On this last point, it is noteworthy to underline that positive organizational creativity means the high value of the above mention six sub-dimensions. Conversely, lack of originality, compatibility, malleability, competitive advantage, appropriability and internal fit refers to negative organizational creativity.

The first creative novelty involves originality - necessary but not sufficient for creativity (Runco, Jaeger, 2012; Sawyer, 2012). In laying the foundation for understanding creative originality, one should distinguish the magnitude of novelty that refers to the extent to which a new entrepreneurial venture (in the author's words, a new idea) is new to the market in terms of new and existing knowledge (Bruton, Filalotchev, Si, Wright, 2013). The second generic attribute of creative novelty is compatibility. Van den Ven and Lifschitz (2013) recommend the reintroduction of the reasonable model of administrative behaviour to the mainstream studies of organizations. Reasonable behaviour represents a collective defined appropriate behaviour (norms, values, logics, and rules that society views as the fair and legitimate behaviour of a person) for a given role and circumstance. Borrowing such logic, the author proposes that the new idea is compatible when the following behaviour is reasonable. The final characteristic of creative novelty is the malleability of the idea. This sub-dimension means the extent to which important elements of the creative ideas have undergone substantive change since being first formulated (Furr, Cavarretta, Garg, 2012). The malleability shapes organizational creativity potential consisting of two elements: (a) the range of new ideas' configurations during the implementation, (b) the speed of transition between the possible postintroduction configurations.

For creative usefulness, the author proposes that new ideas have benefits when organizational members will have positive evaluations of these ideas in terms of competitive advantage and appropriability. In addition, organizational members must believe that a proposed new idea is an appropriate response to a situation as indicated by internal fit. In other words, the author identified three factors that influence the likelihood of positive new ideas' evaluation regarding their utility - relative competitive advantage, appropriability and internal fit.

Competitive advantage is the advantage over competitors gained by offering consumers greater value; it is the firm's position in the competitive landscape that allows the firm to operate in more effective ways than the firms it competes with (Rindova, Ferrier, Wiltbank, 2010). The creativeness of the solution - and even the problem in many cases - provides the focal 
firm with a stronger potential advantage over its rivals. The second subdimension of creative usefulness is appropriability, which refers to the possibility of capturing the returns from the exploitation of creative ideas and preventing others from doing so (Levin, Klevorick, Nelson, Winter, 1987).

In other words, appropriability connotes a firm's effectiveness in capturing the greatest share of future creative ideas spawned by its existing ideas. Lyngsie, Linder, Foss and Zahra (2013) argue that the intensity with which firms evaluate new ideas (i.e. new business opportunities) is associated with the combined presence of organic structure, objective performance appraisals and the presence of rewards for teamwork, knowledge sharing and innovativeness. Following this idea, the author proposes internal fit as the last sub-dimension of creative usefulness, that is positive performance joins organizational creativity when the managerial infrastructure - strategy, organizational culture, leadership, organization design and people - provides a context in which organizational creativity achieves internal fit and sustainable competitive advantage can accrue to the organization.

Research in organizational studies approached the context construct with different foci (Muehlfeld, Sahib, Van Witteloostuin, 2012). They delve with increased focus into the contextual factors that change the nature of the relationship between strategic entrepreneurship and various manifestations of firm performance (Zahra, 1993). The different measures that have been used in strategic management theory and corporate entrepreneurship theory to describe the task environment fall generally into three categories: dynamism, hostility, and complexity (see Bratnicka, 2014; Bratnicka, Dyduch, 2014; Rosenbusch, Rauch and Bausch, 2013 for a detailed review). Dynamism in the environment is manifested by the rate of unpredictable (because of the interconnections between environmental factors) and rapid environmental change included customer tastes, product or service technologies, and modes of intensity of competition - and, thus, heightens uncertainty for organizational members. Hostility in the environment is evidenced by the level of a general lack of opportunities and resources available to firms from environment and competition for these resources (e.g. severe regulatory restrictions, shortage of labour or raw materials, decreasing markets) that influence the extent to which environment can hinder sustained organizational stability and growth. Complexity refers to the level of complex knowledge that understanding the environment requires - the degree of heterogeneity (environmental differences that require 
different organizational practices) which make understanding it difficult and require more information processing.

The author supposes that the advantages of organizational creativity may be influenced by environmental context in which the firm is embedded. Thus, a dynamic environment results in superior performance through the adoption of an organizational creativity that leads firms to focus on innovative strategies and the flexibility of their resource base. Next, to perform well in hostile environments, firms should implement a strategic orientation characterized by low risk taking and experimentation. The above theoretical arguments suggest that organizational creativity is positively related to environmental hostility. Firms with a high degree of organizational creativity will be better placed to explore and exploit these opportunities, and thus, translate the advantages of a complex environment into increased financial performance. Because organizational creativity is an adequate response to a complex environment, the author proposes that organizational creativity is positively related to environmental complexity. Combining dynamism, hostility, and complexity leads to a supportive task environment. On the other hand, a hindering task environment is stable, benevolent, and simple.

\section{FROM CONTRIBUTION TO INTERPLAY}

Creativity plays an important role in the coevolution of an organization with its environment. Employee creativity is an important source of competitive innovation (Amabile, 1996; Oldham, 2003). Recent research suggests that a firm's ability to manage team's dynamics toward creativity constitutes a dynamic capability that provide a competitive advantage over competition (Im, Montoya, Workman, 2013). Creativity as a source of competitive advantage has been developed in contemporary strategic management (Goodman, Dingli, 2012). Managers adept at managing creativity develop superior resources which support competitive advantage (Peteraf, 1993). The creativity is intertwined with corporate strategy development by which firms attain competitive advantage (Junarsin, 2009).

More recently, complexity science and studies of complex adaptive systems have been propounding a view emphasizing the interactions between heterogeneity and independence in the emerging nature of order and disorder (Antonacopoulou, 2014). Applications of these principles of complexity science to the coevolving of the organization and its environment have shed new light on the dynamic nature of creativity in organizations, 
drawing attention to interactions as a key to understanding the fluid emergent and self-organizing nature of organizational creativity. This implies a need to understand the power of interactions between organizational creativity and task environment.

The author suggests that the effect on firm's performance is contingent on multiple organizational creativity and task environment influences. This underlines the crucial role of an interactionist theoretical perspective for developing an in-depth understanding of the antecedents of firm performance. An interactionist perspective inherently entails more than the joint additive codetermination of creativity through organizational creativity and task environment context or the interrelatedness of organizational creativity and task environment. It additionally acknowledges the potential of each class of factors to shape the effects of the respective other class of factors on creativity. The classification of interactions based on the nature of the involved factors should be complemented by a more fine-grained conceptualization of the nature (specific patterns) of their interplay.

Zhou and Hoever (2014) built a typology that reveals a complex set of actors - context interactions, as well as ones that show patterns of diminishing gains and diminishing losses. Following their ideas, the author proposes the insight that a joint consideration of organizational creativity and task environment is needed to advance research on firm performance. In this framework the different types of influences interact with each other to affect firm performance and mutually shape each other.

Table 1 presents this new typology. Note that task environment could be a single environmental dimension or a combination of interaction between multiple contextual factors. Likewise, organizational creativity could be one organizational creativity characteristic or multiple characteristics.

Table 1

A new typology describing organizational creativity - effects of task environment interactions on firm performance

\begin{tabular}{l|l|l}
\hline & \multicolumn{1}{|c}{ Task } & \multicolumn{1}{c}{ environment } \\
\hline $\begin{array}{l}\text { Organizational } \\
\text { creativity } \\
\text { characteristics }\end{array}$ & Supportive & Unsupportive \\
\hline Positive & $\begin{array}{l}\text { Synergistic } \\
\text { Diminishing gains in firm performance }\end{array}$ & $\begin{array}{l}\text { Inhibitory } \\
\text { Remedial for firm performance }\end{array}$ \\
\hline Negative & $\begin{array}{l}\text { Inhibitory } \\
\text { Remedial for firm performance }\end{array}$ & $\begin{array}{l}\text { Antagonistic } \\
\text { Diminishing losses in firm performance }\end{array}$ \\
\hline
\end{tabular}

Source: author's own. 
To organize this variety, the author uses a relatively simple two-by-two scheme that differentiates between organizational creativity and task environment influences on the basis of their presumed or observed positive or negative impacts of creativity. While lacking (conclusive) data, the author aims to make an informed choice based on theoretical reasoning. At the same time, using this scheme provides important insights on how to refine to better capture the current knowledge of how organizational creativity and task environment interact to impact firm performance.

The interplay of positive organizational creativity characteristics and supportive task environment is predominantly thought to benefit firm performance. Although a nuanced account of its consequences is starting to emerge, creativity is still seen as a vital means for organizations to thrive in a dynamic, hostile and complex environment, respond to unforeseen challenges, and proactively develop new capabilities (Baron, Tang, 2011; Bratnicka, 2014; Subramanian, Youndt, 2005). Austin, Devin, Sullivan (2012) suggest that a turbulent environment is positive for the creative process. Viewed together, these research findings indicate that environment influences several aspects of creative behaviour, and simultaneously, important elements of organizational creativity. More generally, the interplay of positive organizational creativity and supportive task environment is a combination of factors that are predominantly thought to benefit firm performance. Such type of interaction comprises cases where individually positive effects affect the firm performance in such a way that their positive effects are mutually reinforced in a synergistic way. This stream of research summarized above, converges towards the inference that leads to the following propositions:

Proposition 1: A supportive task environment strengthens the positive relationship between positive organizational creativity and firm performance.

Alternatively, a supportive task environment as a moderator may create the boundary conditions for positive organizational creativity. The result is a pattern that can be described as diminishing gains. An example of this pattern is McKinley, Latham and Braun's (2014) findings that innovations of certain types might drain a firm of critical resources, thereby worsening its performance and precipitating its individual demise. Hence:

Proposition 2: A supportive task environment weakens the positive relationship between positive organizational creativity characteristics and firm performance.

Although organizational creativity is often seen as a lever of firm performance, it frequently loses its effectiveness. Identifying the sub- 
dimensions that contribute to its downfall is one of the most overlooked factors in organizational literature on effectiveness. Most of research on organizational creativity has focused on factors that are potentially positive rather than on those that hinder or reduce creativity. Turning a blind eye to these factors means forgoing the opportunity to detect existing barriers and inhibitors that might be removed to benefit organizational creativity or to identify conditions that allow firms less inclined to engage in creative strategy to perform more effectively.

Unfortunately, this theoretical review reveals a specific blind spot with regard to investigating negative organizational creativity characteristics as well as an unsupportive task environment. The author now asks readers to suspend disbelief and engage in a brief thought experiment that stakes out the interactions between positive as well as negative organizational creativity characteristics and unsupportive task environment. This experiment is based on the theory of organizational creativity, entrepreneurship, and organization and management theory. Hence, the nature of three types of interactions is depicted on strictly theoretical grounds.

Due to the lack of positive organizational creativity and the hindering environmental context research present, the author extends the entrepreneurship and environment findings to organizational creativity. Environmental hostility promotes safer marketing strategies and hinders riskier innovative strategies (Tang, Hull, 2012). The high level of environmental dynamism is likely to negatively affect entrepreneurial growth (Wiklund, Patzelt, Shepherd, 2009). Moreover, organizations can intend to create new places to shape their environment (Alexy, George, \& Salter, 2013). In dynamic markets, firms need to continuously be on the lookout for new opportunities (exploration), in addition to exploiting existing resources, because the duration of an existing competitive advantage is very uncertain (Bingham, Eisenhardt, 2008; Brown, Eisenhardt, 1997). This suggests the increased and constant need for organizational creativity in dynamic environments. In contrast, traditional and more stable markets are characterized by longer periods of stability followed by shorter episodes of change, and may hence be more forgiving than more dynamic markets (Davis, Eisenhardt, Bingham, 2009). This may allow firms to focus on exploitation (i.e. creative usefulness) for longer periods before they need to pay increased attention to exploration (i.e. creative novelty), even though ultimately both are needed (Bingham, Eisenhardt, 2008; Brown, Eisenhardt, 1997).

Following the general thrust of this research stream the focus is on the interplay of positive organizational creativity characteristics that facilitate 
firm performance, and the unsupportive task environment that directly restricts creativity or indirectly hinders it by reducing the positive relation between organizational creativity and firm performance. This logic is captured in the following propositions:

Proposition 3: An unsupportive task environment nullifies or inhibits the otherwise positive effects of organizational creativity characteristics.

Proposition 4: Positive organizational creativity characteristics provide remedial resources or alternatively reduce or even reverse the negative effects of an unsupportive task environment.

Under some conditions, managers may achieve a turnaround through rigidity and the risk avoidance it implies (Staw, Sandelands, Dutton, 1981), i.e. by avoiding innovation that fails to generate revenues and entails high cost. This indicates that sometimes organizational creativity characteristics may restrict or reduce firm performance. However, a supportive task environment may facilitate firm performance to a large extent, given certain negative organizational creativity characteristics. In this vein, the effects of low creative novelty probably will be weaker in stable environment conditions. For the interplay of negative organizational creativity characteristics and a supportive task environment, two basic patterns may emerge. On the one hand, negative organizational creativity characteristics can nullify or hinder the positive effect of task environment. Conversely, a supportive task environment may provide remedial resources or alternatively weaken the effects of negative organizational creativity characteristics, expressed in the following propositions:

Proposition 5: Negative organizational creativity characteristics nullify or inhibit the otherwise positive effects of a supportive task environment.

Proposition 6: A supportive task environment provides remedial resources or even reverses the effects of negative organizational creativity characteristics.

Finally, there is an interplay of organizational creativity characteristics that are detrimental to firm performance and an unsupportive task environment. In interactions involving these two negative factors, an unsupportive task environment may increase the detrimental effects of negative organizational creativity characteristics. Conversely, interactions involving negative organizational creativity characteristics and an unsupportive task environment may reverse the potentially negative firm performance effect. The result of this pattern can be described as diminishing losses. Hence:

Proposition 7: Interactions of negative organizational creativity characteristics and unsupportive task environment reduce firm performance. 
Proposition 8: Interactions of negative organizational creativity characteristics and unsupportive task environment leads to diminishing losses in firm performance.

The above discussion shows systemic variation within each type of interactions. This is particularly evident when focusing organizational creativity characteristics of the same valence for which the combination of high levels of two or more positive or negative factors cancel each other, or of two or more positive or negative factors does not really yield highest or lowest levels of firm performance. Reflecting this, a final type of interaction, called configurational, involves certain factors that are not individually helpful or harmful but that specifically promote or hinder firm performance in particular configurations with other factors. Although this pattern may be rare, it is potentially interesting. Hence the following testable proposition.

Proposition 9: The configuration of organizational creativity characteristics and task environment dimensions is associated with performance.

\section{DISCUSSION}

One critical task is to address when organizational creativity-task environment interactions will lead to better firm performance. The author also highlights the areas requiring additional attention. To better understand creativity in all its complexity and potential, an interactionist perspective that emphasize organizational creativity-task environment interactive effects on firm performance is used. Toward this end, a typology is proposed that reveals a complex and intriguing set of organizational creativity-task environment interactions, including ones that are synergistic, antagonistic, inhibitory, remedial, and configurational, as well as ones that show patterns of diminishing gain and diminishing losses in firm performance. This creates unique opportunities to study the mechanisms through which interactional factors exert their influence. Turning a blind (or at least myopic) eye to these factors means foregoing the opportunity to detect existing contextual barriers and inhibitors that might be removed to benefit firm performance or to identify conditions that allow firms that are ceteris paribus less inclined to engage in creative processes to perform more effectively. These developments are promising and important, yet their practical value ultimately depends on the ability to combine this diversification with sustained efforts to integrate the findings into a larger, coherent picture.

This extended conceptualization incorporating the nature of both factors and of the interplay between them entails a number of potential benefits. 
First, it leaves room to incorporate factors that are not inherently positive or negative. One key conclusion from this review is that the uniform main effects are rare, and that such open-ended classification is likely to apply to a broader range of factors beyond the structural variables. Moreover, it allows us to capture meaningful variance in the organizational creativity resulting from a combination of different factors that is not captured by the effects associated with the individual factors themselves. Likewise, by alerting researchers to the existence of this variability, the author hopes to stimulate theory building on the conditions under which different factors interact synergistically, yield diminishing returns, or reverse their effects. Finally, from a managerial standpoint, the extended conceptualization highlights that for a complex phenomenon like organizational creativity, different creativity and task environment measures to promote firm performance need to be coordinated carefully to avoid situations in which measures that might have individual merit combine either to yield diminishing returns or even to create detrimental joint effects in firm performance.

In terms of managerial implications, the interactions effects revealed in this study imply that managers should not pursue creative activities without taking context into account. Rather, they should be aware of boundary conditions that can constrain the positive impact of creativity on firm performance. This implies that the relationship between organizational creativity and firm performance could be strategically managed to a certain degree. Future research efforts can uncover even more environmental dynamics that will help both academics and practitioners better understand this vital relationship.

Beyond the needs identified by the gaps the author exposed above as well as the study of when different interaction patterns occur, the study review points to another future research direction. One type of context, the cultural context in which creativity takes place, deserves particular future attention. The existing research allows for little systematic comparison of how different factors play out across different national or cultural contexts, as there is limited overlap between the factors and combinations of factors studied in different national settings. This leaves considerable room for improvement in the understanding of how cultural factors affect organizational creativity and its relationship with task environment. Among the many avenues for future research in this regard, one particularly promising route would be to compare the effect and nature of interactions between organizational creativity and task environment across cultures of varying degrees of cultural tightness and looseness (Gelfand, Nishii, Raver, 2006). 
An issue worth considering is whether it makes sense for firms to always try to simultaneously enhance all organizational creativity dimensions. It is indeed likely that, as with other performance outcomes for firms, enhancing sub-dimensions of organizational creativity may be more or less desirable depending on understanding the underlying conditions. Firms would have to evaluate the trade-offs deciding whether or not to enhance given subdimensions or a set of sub-dimensions. For instance, in a dynamic and hostile environment where new competitive products are continuously being launched, being able to generate original ideas may be more important than trying to figure out how to marginally improve the monetization of a given idea. Another sub-dimension - internal fit - is likely to foster relatively speedy creative idea since building on existing organizational knowledge enables the firm to respond faster than entering a knowledge space anew. This could be advantageous in the short run and in dynamic environments where speed is important. However, such an organizational creativity strategy may also be a source of rigidity in the long run. Therefore, identifying the conditions under which a particular sub-dimension of organizational creativity is favoured over the other would indeed be an exciting and useful research direction.

If characteristics influence organizational creativity, in general, the author might also expect the influence on organizational outcomes. However, this relationship is highly complex. Recognizing the range of organizational creativity sub-dimensions including creative novelty, in concert with creative usefulness, may allow scholars a rich opportunity to explore the true nature of the relationship between organizational creativity and firm performance. One fruitful area for future research is the cyclical or iterative nature of organizational creativity sub-dimensions and performance. It is likely that firm performance will shape subsequent inputs to organizational creativity sub-dimensions, from creative originality to internal fit. The relationship between organizational creativity and performance may be reinforcing: initial sub-dimensions influence initial performance, which influence future sub-dimensions, and so on. Future work could refine this iterative model, identify other important dimensions, and investigate potential limits or boundaries to the influence of organizational creativity sub-dimensions.

The next challenge of analyzing organizational creativity in environmental context is to move beyond correlational patterns to exploring causality. Given the unstructured nature of interactions, the patterns observed are often open to a wide range of possible casual explanations. 
These are alluring opportunities to engage in "management engineering" that go beyond more typical management research by bringing theory and practice together with much faster cycle times between the identification of promising theoretical insight and the testing of that insight with a welldesigned intervention that can help to both advance management knowledge and address pressing practical questions. For management researchers, the result of such intervention is that these are unprecedented opportunities to notice potentially important variables that previous studies might have failed to consider at all, due to their necessarily more focused nature. A management engineering approach can tell us more about organizational practices and behaviours than typical current data-collection methods allow - and have the potential to transform theory and practice.

Finally, Raisch, Birkinshaw, Probst, and Tushman's (2009) review of the ambidexterity research called for more research on boundary conditions (see also Birkinshaw, Gupta, 2013; Junni, Sarala, Taras, Tarba, 2013). Following these ideas, the author proposes that more research is needed to better understand the role of industry dynamics in organizational ambidexterity. For instance, we need a better understanding of the specific aspects of dynamism (i.e. the fast pace of change, complexity, ambiguity, and unpredictability) in organizational creativity. Most empirical organizational creativity studies have considered industry effects as controls rather than moderators of the organizational creativity - firm performance relationship. Moreover, management of innovation could be particularly important for high-technology firms that exist in a fast-paced technological environment or for service firms that rely primarily on intangible assets and knowledge in providing a superior customer experience. In line with this contingency perspective, it can be argued that the effects of organizational creativity could be industry specific. Exploration (i.e. creative novelty) was more important for performance in high-technology and service industries; exploitation (i.e. creative usefulness) appeared to be more important in manufacturing industries. Thus, it is important to examine the boundary conditions of organizational creativity studies in terms of the robustness of the organizational creativity and task environment relationships across different industry contexts.

The pointed-out specific directions for future research can contribute to a more coherent and complete body of work on the phenomenon of interactions between organizational creativity and task environment. 


\section{REFERENCES}

Alexy, O., George, G., Salter, A. J., Cui bono? The Selective Revealing of Knowledge and Its Implications for Innovative Activity, "Academy of Management Review”, 38, pp. 270-291, 2013.

Amabile, T. M., Creativity in Context. Westview Press, Boulder, CO, 1996.

Amabile, T. M., Pillemer, J. J., Perspectives on the Social Psychology of Creativity, "The Journal of Creative Behavior", 46, pp. 3-15, 2012.

Antonacopoulou, E. P., Rethinking the Management of Knowledge in Organisations. Paper presented at the annual meeting of the Academy of Management, Philadelphia, 2014.

Austin, R. D., Devin, L., Sullivan, E. E., Accidental Innovation: Supporting Valuable Unpredictability in the Creative Process, "Organization Science", 23, pp. 1505-1522, 2012.

Baron, R. A., Tang, J., The Role of Entrepreneurs in Firm-level Innovation: Joint Effects of Positive Affect, Creativity and Environmental Dynamism, "Journal of Business Venturing", 26, pp. 49-60, 2011.

Becker, J. M., Klein, K., Wetzels, M. G. M., 2012. Hierarchical Latent Variables Models in PLS-SEM: Guidelines for Using Reflective-formative Type Models, "Long Range Planning", 45, pp. 359-394, 2012.

Bingham, C. B., Eisenhardt, K. M., Position, Leverage, and Opportunity: A Typology of Strategic Logics Linking Resources with Competitive Advantage, "Managerial and Decision Economics", 29, pp. 241-256, 2008.

Birkinshaw, J., Gupta, K., Clarifying the Distinctive Contribution of Ambidexterity to the Field of Organization Studies, "The Academy of Management Perspectives”, 27, pp. 287-298, 2013.

Bratnicka, K., Strategic Entrepreneurship and Firm Performance - Restoring the Role of Task Environment [in:] Kaleta, A., Moszkowicz, K., Sołoducho-Pelc, L. (eds.) Zarzqdzanie strategiczne $w$ teorii i praktyce [Strategic Management - Theory and Praxis] WUE, 366, pp. 59-67, Wrocław, 2014.

Bratnicka, K., 2012. Organizational Creativity and Firm Performance: Theory and Measures, "Management research revisited", 1-8. Cardiff Business School/ British Academy of Management, Cardiff, 2012.

Bratnicka, K., Conceptualizing Organizational Creativity Characteristics. The paper presented at the annual meeting of the British Academy of Management, Belfast, 2014.

Bratnicka, K., Dyduch, W., Organizational Creativity and Firm Performance: How Do Environmental Moderators Matter? The paper presented at the annual meeting at European Academy of Management, Valencia, 2014.

Brown, S. L., Eisenhardt, K. M., The Art of Continuous Change: Linking Complexity Theory and Time-Paced Evolution in Relentlessly Shifting Organizations, "Administrative Science Quarterly", 42, pp. 1-34.

Bruton, G. D., Filalotchev, I., Si, S., Wright, M., Entrepreneurship and Strategy in Emerging Economies, "Strategic Entrepreneurship Journal”, 8, pp. 169-180, 2013.

Davis, J. P., Eisenhardt, K. M., Bingham, C. B., Optimal Structure, Market Dynamism, and the Strategy of Simple Rules, "Administrative Science Quarterly”, 5, pp. 413-452, 2009.

Flipo, C., Team Selection of Creative Ideas and Its Implications for Team Creativity. Paper presented at the annual meeting of the Academy of Management, Philadelphia, 2014. 
Furr, N. R., Cavarretta, F., Garg, S., Who Changes Course? The Role of Domain Knowledge and Novel Framing in Making Technology Changes, "Strategic Entrepreneurship Journal", 6, pp. 236-256, 2012.

Gelfand, M. J., Nishii, L. H., Raver, J. L., On the Nature and Importance of Cultural Tightnesslooseness, "Journal of Applied Psychology", 91, pp. 1225-1244, 2006.

Goodman, M., Dingli, S. M., Creativity and Strategic Innovation Management. Routledge, Oxon/New York, 2013.

Harris, J. D., Johnson, S. G., Souder, D., Model-theoretic Knowledge Accumulation: The Case of Agency Theory and Incentive Alignment, "Academy of Management Review", 38, pp. 442-454, 2013.

Im, S., Montoya, M. M., Workman, J. P., Antecedents and Consequences of Creativity in Product Innovation Teams, "The Journal of Product Innovation Management", 30, pp. 170-185, 2013.

Junarsin, E., Creativity and competitiveness, “Globalization”, 8, pp. 1-13, 2009.

Junni, P., Sarala, R., Taras, V., Tarba, S., Organizational Ambidexterity and Performance: A Meta-analysis, "Academy of Management Perspectives", Vol. 27, No 4, pp. 299-312, 2013.

Levin, R. C., Klevorick, A., Nelson, R., Winter, S., Appropriating the Returns from Industrial Research and Development, "Brookings Papers on Economic Activity", 3, pp. 783-831, 1987.

Li, Q., Smith, K., Maggitti, P., Tesluk, P., Katila, R., Top Management Attention to Innovation: The Role of Search Selection and Intensity in New Product Introductions, "Academy of Management Journal", 56, pp. 893-916, 2013.

Lyngsie, N. J., Linder, S., Foss, N. J., Zahra, S. A., Free to Choose? Organizational Context and Evaluation of Opportunities. Paper presented at the $7^{\text {th }}$ Conference on Performance Measurement and Management Control, Barcelona, 2013.

Masucci, M., Brusoni, S., Hayton, J., Exploring the Evaluation and Selection Process of Corporate Ventures: Critical Factors and Stage-based Differences. Paper presented at Babson College Entrepreneurship Research Conference, Ontario, 2014.

McKinley, W., Latham, S., Braun, M., Organizational Decline and Innovation: Turnarounds and Downward Spirals, "Academy of Management Review", 39, pp. 88-110, 2014.

Muehlfeld, K., Sahib, P. R., Van Witteloostuin, A., A Contextual Theory of Organizational Learning from Failures and Successes: A Study of Acquisition Completion in the Global Newspaper Industry, 1981-2008, "Strategic Management Journal”, 33, pp. 938-964, 2012.

Oldham, G. R., Stimulating and Supporting Creativity in Organizations [in:] Jackson, E. S., M. A. Hitt, A. M., Nisi, S. A., (eds.) Managing Knowledge for Sustained Competitive Advantage, pp. 243-273. Jossey-Bass, San Francisco, 2003.

Peteraf, M. A., The Cornerstones of Competitive Advantage: A resource-based View, "Strategic Management Journal", 14, pp. 179-191, 1993.

Porter, M. E., Rivkin, J. W., The Looming Challenge to U.S. Competitiveness, "Harvard Business Review", 42 (5), pp. 35-36, 2012.

Raisch, S., Birkinshaw, J., Probst, G., Tushman, M. L., Organizational Ambidexterity: Balancing Exploitation and Exploration for Sustained Performance, "Organization Science", 20, pp. 685-695, 2009. 
Rindova, V., Ferrier, W. J., Wiltbank, R., Value from Gestalt: How Sequences of Competitive Actions Create Advantage for Firms in Nascent Markets, "Strategic Management Journal", 31, pp. 1474-1497, 2010.

Rosenbusch, N., Rauch, A., Bausch, A., The Mediating Role of Entrepreneurial Orientation in the Task Environment - Performance Relationship: A Meta-analysis, "Journal of Management", 39(3), pp. 633-659, 2013.

Runco, M. A., Jaeger, G. J., The Standard Definition of Creativity, "Creativity Research Journal", 24, pp. 92-96, 2012.

Sarooghi, H., Libaers, D., Burkemper, A. C., Examining the Relationship between Creativity and Innovation: A Meta-analysis. Paper presented at the annual meeting of the Academy of Management, Philadelphia, 2013.

Sawyer, R. K., The Science of Human Innovation. Explaining Creativity. Oxford University Press, New York, 2012.

Staw, B. M., Sanderlands, I. L., Dutton, J. E., Threat Rigidity Effects in Organizational Behavior: A Multilevel Analyses, “Administrative Science Quarterly”, 26, pp. 501-524, 1981.

Subramanian, M., Youndt, M. A., The Influence of Intellectual Capital on the Types of Innovative Capabilities, “Academy of Management Journal”, 48, pp. 45-463, 2005.

Tang, J., Hull, C., An Investigation of Entrepreneurial Orientation, Perceived Environmental Hostility, and Strategy Application among Chinese SMEs, "Journal of Small Business Management", 50, pp. 132-158, 2012.

Van den Ven, A. H., Lifschitz, A., Rationale and Reasonable Microfoundations of Markets and Institutions, "Academy of Management Perspectives", 27, pp. 156-172, 2013.

Wiklund, J., Patzelt, H., Shepherd, D., Building an Integrative Model of Small Business Growth, "Small Business Economics", 32, pp. 351-374, 2009.

Zahra, S., Environment, Corporate Entrepreneurship, and Financial Performance: A Taxonomic Approach, "Journal of Business Venturing”, 8, pp. 319-340, 1993.

Zhou, J., Hoever, I. J., Research of Workplace Creativity: A Review and Redirection, "The Annual Review of Organizational Psychology and Organizational Behavior”, 1, pp. 333-359, 2014.

Received: October 2014, revised: April 2017

Disclosure statement: The author is not aware of any affiliations, memberships, funding, or financial holdings that might be perceived as affecting the objectivity of this review. 